Kathmandu School of Law Review (KSLR),

Volume 8, Issue 1, 2020, pp 40-49

https://doi.org/10.46985/kslr.v8i1.2127

(C) KSLR, 2020

\title{
From Precariousness to Prudence: Eco-Cosmopolitanism as the Fabric for Weaving the Post-COVID World
}

\author{
Nabanita Samanta*
}

\begin{abstract}
In a crucial juncture when the whole world has been shattered by the reign of a tiny virus invading the apparently invincible empire of human 'civilization', the plaguing pandemic has brought to the fore fundamentally interconnected nature of our collective existence and consequently our shared vulnerability. COVID-19 as essentially a zoonotic disease accentuates the anthropogenic hazards inflicted on the ecosystem resulting in spilling over of such pathogens from animals to bumans. It also nudges us to reflect on our fundamentally interconnected existence which we have long remained oblivious about. The prevailing obliviousness seems to have emanated from willful ignorance or selfdeceptive knowledge rooted in over-arching dictates of anthropocentrism; however on the structural front, the roots can be traced back to the capitalistic system perpetuating the 'bomo economicus' aspirations so as to mark the unflinching triumph of the 'Capitalocene'. While pushing and pulling ourselves to adapt to the 'new normal', it becomes an imperative to go beyond the myopic vision of restricting ourselves to shortterm mitigation measures like border-closure or vaccination; instead time is ripe for taking a critical and broad-based stance on the structural roots of the current pandemic such that restructuration of post-COVID world helps shoving aside such calamitous disaster in days to come. It is in this regard, a radical take on 'cosmopolitanism' seems the need of the hour to fill the lacunae in the existing mode of perusing interconnectedness that operates only on the surface level in the name of 'globalization' and overlooks the fundamental rubric of ecological integrity. While shedding some light on the nexus that this pandemic shares with the evils of capitalistic enterprise and neoliberal culture of globalized consumerism, this paper, within its limited scope, will make an attempt to find an antidote to the current crisis through endorsing an 'eco-cosmopolitan' worldview wherein the rationalized 'instrumentalization' of environment and wild animals gets overridden by an eco-centric perspective on our fundamentally interconnected existence.
\end{abstract}

* Nabanita Samanta is a graduate student pursuing Masters in Sociology at the University of Hyderabad, India. Her research-interest broadly lies at the intersection of ecology, society and the self. She can be reached at nabanitasamanta097@gmail.com.

This paper was awarded the 2nd Best Paper in the International Research Paper Writing Competition, organized by Kathmandu School of Law Review, Amnesty International Fusion Youth Network, and the Cognition Club. 


\section{Introduction:}

'The future always arrives too fast...' (Alvin Toffler')

Given the rapid strides of fetishized economic growth, unmindful surge in global consumerism, profiteering motives of complicit government and self-indulgent individuals, it was inevitable that the human 'civilization' would someday get crumbled under the wheels of its own 'progress'; but nobody would have predicted it happening so early! Or perhaps we had remained so much obsessed with sustaining the momentum of our ambitious 'progress' at any cost that we had conveniently overlooked the dystopian future lurking before us just beneath the horizon! Transgressing the 'planetary boundaries $^{2}$ one after the another and confronting the deleterious consequences emanating from such disruption could not deter us from the path of limitless 'progress' even in a world severely constrained by the limits of finitude and fragility. However, as now we have turned to face the future that we never thought would arrive so fast and so sudden, we find ourselves pummelled by the waves of overwhelming changes brought by the plaguing pandemic of COVID-19 and its rippling effects percolating down to every walk of our life.

While hurtling through the insurmountable hurdle of a planetary crisis, we may end up embracing the fear and trepidation; or we can turn our precarious present into a call for prudent action to pave the path for a future habitable for us and hospitable for generations to come. Aghast at the baffling uncertainties brought by the months-long hiatus due to the outbreak of a deadly infectious disease, we may stumble over our socio-economic-political system crippled into a debilitating state; or we may harness the potential of a crisis to turn it into a possibility to redress our collective faults and failures that might have stimulated the infestation of such viruses in recent times. How we choose to respond to the current crisis and rebuild the post-COVID world will determine the long-term sustainability of this 'lonely planet's.

The current pandemic through its zoonotic origin accentuates the cataclysmically dysfunctional relationship of humans with other animals as well as with the larger environment. Such disruption marking a rupture in the ecological integrity is very much imbricated in the larger socio-cultural and political context. Thus, it becomes an imperative for us to look beyond the short-term measures of lockdown and borderclosure for containing the spread of the disease; even vaccines and medicines seem inadequate to bring permanent respite as there remains a strong probability of reemergence of such pandemic and proliferation ${ }^{4}$ of more deadly viruses unless the

Alvin Toffler, The Future Shock, Bantam Books, New York, 1971.

Johan Rockstrom et al., 'Planetary Boundaries: Exploring the Safe Operating Space for Humanity', Ecology and Society, volume 14: 2, 2009.

3 As Maya Angelou has described, quite persuasively and figuratively as well, our common habitat as "a small and lonely planet" (which nicely captures our collective vulnerability as well as our shared responsibility to our common habitat) in her fascinating poem titled 'A Brave and Startling Truth'.

4 World Economic Forum \& Harvard Global Health Institute, "Outbreak Readiness and Business Impact: Protecting Lives and Livelihoods across the Global Economy", January 2019, available at https://www. weforum.org/reports/outbreak-readiness-and-business-impact, accessed on 22 January 2021. 
underlying causal factors are addressed at their roots.

Standing in this hyper-globalized world, this plaguing pandemic has once again brought to the fore interconnected nature of our collective existence and consequently our shared vulnerability. Despite living in a 'networked society', we have long remained oblivious of this intricate interconnectedness while being immersed in our willful ignorance or self-deceptive knowledge rooted in over-arching dictates of anthropocentrism, the belief that fallaciously puts humans at the center of reality and thereby undermines the fundamental law of the biosphere i.e. interconnectedness and interdependence. Or perhaps our all-pervasive reluctance has been emanating from an inescapable epistemic fallacy shrouded under a pervasive qualm to facilitate the 'homo economicus' aspirations and to mark the unflinching triumph of the 'Capitalocene'. Therefore, it becomes a timely endeavor to delineate the trajectory of the present precariousness brought by the COVID-19 pandemic. While pushing and pulling ourselves to adapt to the 'new normal', we must strive to go beyond the myopic vision of restricting ourselves to mitigation measures taken on the surface-level; instead it is of utmost exigency that we take a critical and broad-based stance on scrutinizing the current crisis such that restructuration of post-COVID world helps shoving aside such calamitous disaster in days to come.

\section{Behind the Precarious Present: Pandemic-ravaged World}

\section{'If you actually want to create global pandemics, then build factory farms.' (Michael Greger ${ }^{7}$ )}

Widespread speculations and careful scrutiny are underway to trace the origin of the corona virus which has swept the world and vanquished the mighty empire of human 'civilization'. While several researches have discerned the progenitor of the corona viruses (SARS-CoV) to be the bats, some ascertain the host of the COVID-19 pandemic to be the pangolins ${ }^{8}$, the scaly anteaters which are unfortunately the most trafficked wild mammal on the planet?. While the search for the animal origin of the current imbroglio is still going on, several media reports have highlighted the role of Chinese 'wet markets' as the current pandemic is believed to have originated from one such wildlife market in Wuhan. Such speculation has led the United Nations to declare a complete ban on such wildlife markets operationalized in different parts of

Manuel Castells, The Rise of the Network Society, Blackwell, Oxford, 1996.

Jason W. Moore, 'The Capitalocene, Part-1: On the nature and origins of our ecological crisis', The Journal of Peasant Studies, 2017, available at https://www.tandfonline.com/doi/full/10.1080/03066150.2016.1235 036, accessed on 22 January 2021.

7 Michael Greger, Bird Flu: A Virus of Our Own Hatching, Lantern Books, Brooklyn, 2006.

8 To know more about pangolins and the status of their endangerment, go through this blog of the IUCN SSC Pangolin Specialist Group: https://www.pangolinsg.org/.

9 Wufei Yu, 'Coronavirus: Revenge of the Pangolins?' The New York Times (New York, 5 March 2020, available at https://www.nytimes.com/2020/03/05/opinion/coronavirus-china-pangolins.html, accessed on 25 July 2020. 
the world ${ }^{10}$. However, such mandate is less likely to be implemented in letter and spirit considering the vested interests and profiteering motives involved in operationalization of such wildlife markets. Moreover, it becomes essential to arrange alternative means of livelihood for the large number of people who solely depend on trading wildlife, otherwise this abrupt ban will only accelerate the magnitude of illegal trading and animal trafficking which will further intensify the crisis. Also, with regard to the question of 'wet markets' there is an inclination to 'racialize"11 this aspect by passing on the blame to 'others', for instance in the case of the current pandemic the blame has been passed on to China. But if we consider the generalized trend of such zoonotic diseases emerging on a pandemic-level, the territorial origin varies, for example, Nipah virus originated first in Malaysia while Ebola virus had its origin in Africa, West Nile virus and Lyme Disease had the origin in the US. Thus, it would be fallacious to either racialize or politicize this aspect based on antagonism among nation-states; rather it would be wise enough to address the 'big picture' lurking behind such discrete instances.

Notwithstanding the debates and discontents concerning the origin of the current pandemic, it can be discerned with certitude that COVID-19 is essentially a zoonotic disease which transmits from animals to humans. It is important to note that most of the infectious diseases that have shaken the world or parts of the world in the preceding few decades are primarily zoonotic. For instance, some of the tremor-invoking diseases in the recent past are Ebola, Nipah, SARS, SADS, Avian Influenza $\left(\mathrm{H}_{5} \mathrm{~N}_{1}\right)$ etc., all of which can be broadly grouped as zoonotic disease. Several studies have highlighted that the outbreak of zoonotic diseases has been on rise in recent times ${ }^{12}$. However, it would be a folly to pass the blame on host-animals, be it bats or pangolins or some other animals; rather we should look at such outbreak as a symptom of a larger problem. In case of zoonotic diseases, the pathogens that generally take animals as their hosts get transmitted to humans in favorable conditions. Such spillover of pathogens from animals to humans is spurred by a constellation of reasons starting with destruction of animal habitat, biodiversity loss, climate change, commercialization of farming, and consumerism-driven market for trading exotic animals as well as animal trafficking etc.

Loss of habitat for the wild animals while pushing the respective animals to distress and deprivation also put humans in jeopardy as it causes much more frequent contacts of humans with disease vectors. Apart from destruction of habitat, zoonotic diseases are on the rise due to expansion and intensification of animal agriculture. ${ }^{13}$ Industrialization

\footnotetext{
10 Patrick Greenfield, 'Ban wildlife markets to avert pandemics, says UN biodiversity chief' The Guardian, 6 April 2020, available at https://www.theguardian.com/world/2020/apr/06/ban-live-animal-marketspandemics-un-biodiversity-chief-age-of-extinction, accessed on 28 July 2020.

11 Thom van Dooren, 'Pangolins and Pandemics: The Real Source of This Crisis in Human, Not Animal', newmatilda.com, 22 March, 2020, available at https://newmatilda.com/2020/03/22/pangolins-andpandemics-the-real-source-of-this-crisis-is-human-not-animal/, accessed on 23 July 2020.

12 Katherine F. Smith et al., 'Global Rise in Human Infectious Disease Outbreaks', Journal of the Royal Society Interface, volume 11: 101, 2014, available at https:/ / royalsocietypublishing.org/doi/10.1098/rsif.2014.0950, accessed on 20 January 2021.

13 Jason W. Moore, 'The Capitalocene, Part-1: On the nature and origins of our ecological crisis', The Journal of Peasant Studies, 2017, available at https://www.tandfonline.com/doi/full/10.1080/03066150.2016.1235 036, accessed on 20 July 2020.
} 
of animal agriculture is as much a reason for meeting the demands of more food for the increasing population as for keeping up pace with the rising demands for meat and animal products. There has been a significant increase in a handful of selected animals (the ones which are domesticated as livestock) at the cost of a wide variety of wild mammals. Bar-On, Philips and Milo in their recent findings pertaining to a comparison of current global biomass with that of pre-human era has illustrated that the biomass of wild mammals has shrunk by a factor of six while the total biomass of all mammals has witnessed an almost four-fold rise ${ }^{14}$. This contemporary furor and frenzy of exponentially increasing the number of a few particular animal species used as food or other products while pushing other large number of wild animals to the verge of extinction has been driven by the neoliberal trend of global consumerism. Of late, animal agriculture has been industrialized and globalized on a large-scale as increasing demand for animal products has rationalized the imperative for producing such resources in factory-farms on a level of mass production so as to make those available easily and at a cheap cost. Such industrialized cultivation of animals has serious negative repercussion on the environment in terms of water pollution, land degradation and emission of green-house gases ${ }^{15}$.

With a substantial rise in the number of animals having utilitarian value for human consumers, there has been a consequent decline in the number of wild animals available in the biosphere and it has even resulted in extinction of a wide range of species. This

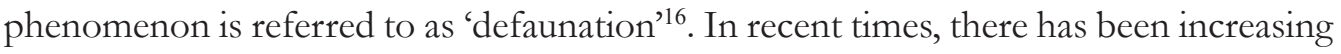
number of studies coming to the light underlining the alarming pace of species decline and extinction i.e. defaunation. We have long remained oblivious of such staggering and shocking level of 'biological annihilation" ${ }^{17}$; thus this pandemic when looked at with all its intricacies needs to be perceived as an alarming call to rethink our current endeavor and reshape our relation with other animals going beyond the modernity-driven notion of 'rationalization' and 'instrumentalization'. This planetary health crisis rooted in the anthropogenic hazards inflicted on the ecosystem thus lays bare our collective amnesia towards 'the animality that we share with other living beings (our four-legged legacy) despite our all-too-buman symbolic (and hence moral, linguistic and socio-cultural) ways of being in the world ${ }^{18}$. But such distorted worldview rooted in the anthropocentric leanings is not merely an ontological problematic operating in a vacuum; rather it is very much embedded

${ }_{14}$ Yinon M. Bar-On \& Rob Philips M. Ron Milo. 'The Biomass Distribution on Earth', Proceedings of the National Academy of Sciences, volume 115: 25, 2018, available at https://www.pnas.org/content/pnas/ early/2018/05/15/1711842115.full.pdf, accessed on 20 July 2020.

15 Henning Steinfeld and others, 'Livestock's Long Shadow: Environmental Issues and Options', Livestock, Environment and Development (LEAD) Initiative, Food and Agricultural Organization (FAO) of the United Nations, 2006, available at http://www.fao.org/3/a0701e/a0701e.pdf, accessed on 24 July 2020.

16 Rodolfo Dirzo et al., 'Defaunation in the Anthropocene', Science, volume 345:6195, 2014, available at https://science.sciencemag.org/content/345/6195/401.full, accessed on 28 July 2020.

17 Gerardo Ceballos et al., 'Biological Annihilation via the Ongoing Sixth Mass Extinction Signaled by Vertebrate Population Losses and Declines', Proceedings of the National Academy of Sciences, volume 114:30, 2017, available at https:/ /www.pnas.org/content/pnas/114/30/E6089.full.pdf, accessed on July 27, 2020.

18 Eduardo Kohn, How Forests Think: Toward an Antbropology beyond the Human, California University Press, Los Angeles, 2013. 
in the structure constituting the socio-political-economic fabric which establishes the COVID-19 pandemic as a 'neo-liberal disease'19.

\title{
Blind-spot of Capitalocene: Distorted Human-Environment Interaction
}

\author{
'Capitalocene is a kind of critical provocation to this sensibility of the \\ Anthropocene, which is: We have met the enemy and he is us.' (Jason Moore ${ }^{20}$ )
}

It is a matter of utter dismay that the propensity to 'manage' the plaguing pandemic of COVID-19 while at the same time maintaining the overarching dictates of 'neoliberal' culture has made us sighing away from initiating a critical interrogation into the root of the pandemic. Or, perhaps it is our shortsightedness that we concentrate more on debating about the animal host that might have transmitted such disease to humans; indeed tracing the exact origin of the virus will have epidemiological significance, but in terms of socio-political intervention to deal with a pandemic it becomes an imperative for us to delve deeper into the structural factors within which the trajectory of the disease is intricately embedded. The root of this deadly disease or for that matter other such infectious zoonotic disease can be traced back to the practice of industrialized animal farming which again is a byproduct of the modernity-driven hegemony of anthropocentrism. It will however entail only a blinkered view if we try to locate this distortion in the cultural realm of 'anthropocentric' worldview; instead we need to delve deeper into the structural factors that have given rise to anthropocentric intervention, much to the own peril of the humans themselves. This brings us to the concept of 'Capitalocene', a neologism that underlines the inconspicuous nexus between planetary crisis (like that of the present pandemic) and the functioning of capitalism. The COVID-19 pandemic, therefore, needs to be analyzed and understood in the broader framework of neo-liberalism. The large-scale animal-farms perceived as main culprit behind outbreak of zoonotic diseases are nothing but an offshoot of global mass culture which promotes certain homogenized consumption-habits. Also, it is the neoliberal lifestyle which prizes the 'purchasing power' of people and consumerism as the cornerstone of 'happiness' while eroding the eudemonic notion of wellbeing ${ }^{21}$. Such dietary culture mediated by a capitalist propaganda while undermining the diversity of local cultures fuels the growth of industrialized animal-farming thereby easing the path for such pandemics. Even the lack of goodwill to address the crisis of species extinction or 'defaunation' can be traced back to the all-pervasive capitalistic enterprises operating subtly through the administrative machineries. ${ }^{22}$

\footnotetext{
19 Rob Wallace et al., 'COVID-19 and Circuits of Capital', Monthly Review, volume 72:1, 2020, available at https://monthlyreview.org/2020/05/01/covid-19-and-circuits-of-capital/, accessed on 28 July 2020.

20 Moore (n 6).

21 Jenia Mukherjee \& Amrita Sen, 'Is Covid-19 a "Capitalocene" Challenge?' Seeing the Woods (A Blog by Rachel Carson Centre), available at https://seeingthewoods.org/2020/05/11/is-covid-19-a-capitalocenechallenge/, accessed on 29 July 2020.

22 Rodolfo Dirzo et al., 'Defaunation in the Anthropocene', Science, volume 345:6195, 2014, available at https://science.sciencemag.org/content/345/6195/401.full, accessed on 28 July 2020.
} 
Addressing the broad question of structural fabric leading to the distortion in humananimal relation, Diana Stuart and Ryan Gunderson in their analysis based on 'critical theory' has highlighted two root drivers behind continual reproduction of such degrading relationship: one is what they have termed as 'capital's ethos' while the other one is 'domination ideology ${ }^{23}$. 'Capital's ethos' refers to the over-arching inclination to reduce a life-form to a mere 'means' towards the 'end' of accumulation of capital through factory production of living animals. 'Domination ideology' implies the ideological stance driven by an infatuation for hardcore 'rationality' of 'instrumentalization' which views 'nature' or any elements in the biosphere including wild animals as nothing more than an instrument to fulfill the unbridled needs of the human beings. Juxtaposition of this structural dimension ('capital's ethos') with the ideological factors ('domination ideology') drives the unrestrained growth of animal agriculture even at the cost of irreversible ecological damage which subsequently prepares the fertile ground for such deadly pandemic to take root. These deeply entrenched structural-ideological factors have paralyzed us so much so that any sensible action to alter the distorted fabric seems a distant dream. Yet, as we are pushing ourselves to negotiate with a potent 'enemy' manifested in the form of the current pandemic, it becomes a matter of utmost exigency that we acknowledge it with due diligence that it is not COVID-19 which we should fight against, rather it is the injustices meted out by the inconsiderate profiteering motives of capitalistic endeavors that we must seek to eradicate. This pandemic therefore stands as a clarion call to address these concerns and raise awareness about such nuances. It is a great pity that it takes a disastrous pandemic to bring the realization that the perilous reshaping of biosphere purely driven by the utilitarian calculus of the humans will not only undermine ecological integrity but also pave the path for extinction of even humans. But, as it is said that it's a folly to let a crisis go in vain; therefore it is a pressing need for us to harness the potential of this crisis to turn it into a possibility for a different future freed from the alarming threats of resurfacing of such pandemics.

\section{From Precariousness to Prudence: Eco-cosmopolitanism as the Panacea}

'We can't solve problems using same kind of thinking that created the problem.' [Albert Einstein]

It's our anthropogenic stance further aggravated by the 'capitalocene' that has made us stand in front of such an unprecedented planetary health crisis. Due to the interconnected nature of the globe, the risks that we are facing are collectively shared (even though in terms of experience the risks are felt unevenly; this aspect of differentiation, imbricated in the unbridled inequalities plaguing the social structure at different levels, is however beyond the scope of this paper), therefore any attempt of devising the solution must take into account this essentially interconnected nature of the biosphere. This pandemic lays bare the fundamental interdependence that exists

\footnotetext{
23 Diana Stuart \& Ryan Gunderson, 'Human-animal Relations in the Capitalocene: Environmental Impacts and Alternatives', Environmental Sociology, 2019, available at https://www.tandfonline.com/doi/abs/10.108 0/23251042.2019.1666784, accessed on 28 July 2020.
} 
among all species and binds all of us together in a symbiotic relationship with the larger environment. We have long remained oblivious of this aspect; our socio-economic structure and political apparatus have further aggravated this insensitivity to reach its zenith. But, at the height of the deadly pandemic, we must once again strive hard to inculcate the essential sensitivity towards: "the revelation of how intimately connected we are to one another and to the rest of nature through the intricate, complex, delicate web of biological and ecological relationships weaving the tapestry of being." ${ }^{24}$.

To endorse such acumen of interconnectedness, it is imperative for us to turn towards 'cosmopolitanism' which needs to be approached from a radical point of view to eliminate the structural injustices very much engrained in the very fabric of the prevailing world order. Indeed, this interconnected nature of this 'global village' has been accentuated by the scholarship on 'globalization' and the international regime of jurisprudence. Standing in a 'risk society ${ }^{25}$, we can no longer keep ourselves immune from the collective vulnerability and shared risks emanating from the faulty sociopolitical order; thus embracing a cosmopolitan outlook while rebuilding the postCOVID world seems prudent and practical. In this connection, it is apposite to recall Martha Nussbaum as she has rightly pointed to the exigency of a cosmopolitan order, "If we are so much as to survive as a species and a planet, we clearly need to think about well-being and justice internationally, and together" ${ }^{26}$. While Nussbaum is right in her insistence on underlining the needs for cooperation and collaboration beyond borders, we need to take a critical stance on the current regime of international order which falls short in eradicating the perils of the 'capitalocene'. Building a sustainable and resilient global order therefore needs to breach the rift between human and environment, thereby taking an eco-centric take on cosmopolitanism - which can be understood as 'ecocosmopolitanism', to borrow the term from Ursula K. Heise ${ }^{27}$.

Eco-cosmopolitanism is a humble reminder to us that we, the humans, are just another inhabitant alongside innumerable elements bounded to one another through a symphony of symbiotic existence while sharing our place on this 'pale blue dot' 28 (as astrophysicist Carl Sagan has put it wonderfully). 'Inter-species equity' ${ }^{29}$ has been emphasized by Graham Haughton in his endeavor of charting out a comprehensive list of principles quintessential for 'sustainable development'. This clearly advocates for 'intrinsic' worth of all species irrespective of their 'instrumental' value. The plausible remedy for the plaguing pandemic lies in this fundamental shift from 'instrumental' and rationalized value prompted by capitalist vested interests towards 'intrinsic' worth

\footnotetext{
24 Linda Lear (ed.), Lost Woods: The Discovered Writing of Rachel Carson, Boston, Beacon Press, 2011.

25 Ulrich Beck, Risk Society: Towards a New Modernity (Trans. Mark Ritter), SAGE Publications, London, 1992.

26 David A. Crocker, 'Functioning and Capability: The Foundations of Sen's and Nussbaum's D London Development Ethic', Political Theory, volume 20:4, 1992, p. 584.

27 Ursula K. Heise, Sense of Place and Sense of Planet: The Environmental Imagination of the Global, Oxford University Press, New York, 2008.

28 Carl Sagan \& Ann Druyan, Pale Blue Dot: A Vision of the Human Future in the Space, Random House Publishing Group, New York, 2011.

29 Graham Haughton, 'Environmental Justice and the Sustainable City', Journal of Planning Education and Research, volume 18, 1999, p. 233.
} 
cherished through eco-centric world order. Going beyond the utilitarian calculus, ecocosmopolitanism calls for a complete revamp in different realms starting with pedagogy to media, from economy to political institutions, from family to community-life and so on. While talking about such a radical development ethic, Latin American liberation theologian Leonardo Boff has ascertained:

\begin{abstract}
Having a new cosmology is not enough. How are we to spread it and bring people to internalize it so as to inspire new behaviors, nourish new dreams, and bolster a new kindness toward the Earth? That is certainly a pedagogical challenge. As the old paradigm that atomized human beings and set them against the universe and the community of living beings permeated through all our pores in our lives and created a collective subjectivity suited to its intuitions, so now the new paradigm must form new kinds of subjectivity and enter into all realms of life, society, the family, media, and educational institutions in order to shape a new planetary man and woman, in cosmic solidarity with the overall direction of the evolutionary process. ${ }^{30}$
\end{abstract}

There can be no denial that there lie myriad challenges in laying the foundation of an international order taking 'eco-cosmopolitanism' as the very fabric. Yet, it is a pressing need and we must gear up to work towards this objective.

\title{
Way-ahead
}

"Our moral responsibility is not to stop the future, but to shape it...to channel our destiny in bumane directions and to ease the trauma of transition." [Alvin Toffler ${ }^{31}$ ]

It is ironical that most of the scholarly discussions regarding the fear-mongering pandemic have been directed towards invention of a vaccine and short-term measures for containment of the outbreak, while the broader view of reshaping the world-order by addressing the structural causes behind the pandemic has remained unaddressed. While debates and discussions are replete with speculations of widespread changes leading to the inception of the post-COVID world as a marked departure from the prevailing order of the world, it is the need of the hour to relocate humans from its audaciously claimed hubristic place in the ecological cosmos of the Earth towards its humble belonging to the biosphere along with the myriad life forms interconnected through symbiotic existence. The hysterical noises of unbounded 'progress' have deafened the harbingers of 'civilization' to their inner voice of primeval belonging and organic harmony. Ruinous public policies driven by self-interest of those in the higher echelons of power further benumb the sensitivity of taking an eco-centric view. Now, while crippling under an unprecedented crisis, we need to take this pandemic as a possibility to dawn in changes in the form of charting out a new world-order woven into the fabric of eco-cosmopolitanism. This requires a monumental shift in consciousness;

\footnotetext{
30 Leonardo Boff. Cry of the Earth, Cry of the Poor, Trans. Phillip Berryman, Orbits Books, New York, 1997.

31 Alvin Toffler, The Future Shock, Bentam Books, New York, 1971.
} 
equally important is to remove the structural and ideological constraints to mark the advent of a harmonious future freed from the recurrent threats of pandemics and planetary hazards. This transformation seems quite utopian to bring to the light of reality; indeed, marking the inception of an eco-cosmopolitan world is marred with numerous challenges, yet much beyond a mere fantasy it is a horizon for dawning in radical transformation - what can be called as 'utopian realism' ${ }^{32}$ ! 